\title{
Retracted: Overexpression of Bacterial $m$ tlD Gene in Peanut Improves Drought Tolerance through Accumulation of Mannitol
}

\author{
The Scientific World Journal \\ Received 21 August 2019; Accepted 21 August 2019; Published 13 December 2019 \\ Copyright (C) 2019 The Scientific World Journal. This is an open access article distributed under the Creative Commons Attribution \\ License, which permits unrestricted use, distribution, and reproduction in any medium, provided the original work is \\ properly cited.
}

The Scientific World Journal has retracted the article titled "Overexpression of Bacterial mtlD Gene in Peanut Improves Drought Tolerance through Accumulation of Mannitol" [1]. As raised on PubPeer, there is image duplication in Figure 2. Further issues were found with the figures and reporting, including when compared with the thesis of the first author [2].

The authors responded and provided some of the original figures and data, which are included as supplementary materials. The authors offered to correct the figures, and they do not agree with retraction. However, their response did not satisfy our concerns and the Editorial Board recommended retraction. A summary of the major concerns is as follows:

(1) Two of the panels in each of Figures 2(e) and 2(f) are identical, i.e., panel 3 of Figure $2(e)$ is the same as panel 1 of Figure 2(f) and panel 4 of Figure 2(e) is the same as panel 3 of Figure 2(f). The authors say the figure duplication was inadvertent.

The same figure duplication also appeared in Figure 4.3 in the thesis. However, the left-hand panels in Figure 4.3A (thesis) and Figure 2(e) (article) are not the same. The authors disputed this and provided a figure they say was from the thesis, which they say shows the left-hand panels in Figure 2(e) are the same as those in Figure 4.3A in the thesis, but the thesis does not show the same image as the authors provided to us.

(2) The distribution of insignificant digits (i.e., digits unimportant to the measured value) is expected to be uniform [3]. The rightmost values in the data underlying Table 3 have a significantly nonuniform distribution.

Other concerns include the following:
(3) Figures 2(a) and 2(b) are the same: both show "deembryonated cotyledons cocultured with Agrobacterium strain LBA4404," but the same view is shown twice. In the thesis, Figures $4.2 \mathrm{~A}, \mathrm{C}$, and D show the same images as Figures 2(a), 2(c), and 2(d) in the article, but Figure $4.2 \mathrm{~B}$ is different from Figure 2(b) in the article. Figure $4.2 \mathrm{~B}$ in the thesis should have been used instead of the image in Figure 2(b) in the article.

(4) Figure 3(d) shows "detection of mtlD gene transcription in transgenic plants using RT-PCR. Lane $N=$ nontransformed line, lanes $1-8=$ transgenic lines (MTD1 to MTD8), bottom row: 18SrRNA as internal control." The left-most seven lanes (including the marker lane) are the same as those in Figure 4.33 in the thesis, which reports "RT-PCR analysis for the T2 transgenic plants before and after stress treatment," showing six strains before and after stress. There is also undeclared splicing in Figure 3(d) between lanes 6 and 7. The authors said the RT-PCR assay in Figure $3(\mathrm{~d})$ only shows the amplification after stress because there is no difference compared to before stress as mtlD is driven by the constitutive CaMV35S promoter. Since there were no significant changes in the expression level, they provided representative images of those eight lines to show the transgene was expressed when RNA was isolated and amplified following the RT-PCR protocol. To show the eight lanes along with the nontransformed line, they cut and pasted the images as one picture; they provided the original unaltered images.

(5) The strain numbering and results in Table 4.24 in the thesis do not match those reported in the article in Table 3. The authors explained that they initially had 
193 plants of mtlD peanut transgenics, out of which only 10 were confirmed positive. For publication, only 8 transgenic lines were taken for further analysis and, for the convenience of readers, the plants were numbered as $1-8$.

(6) A previous study by the authors also on mtlD in peanuts was cited as reference 8 [4], but was not discussed in detail. The authors explained that this Australian Journal of Crop Science article studied plants under salinity- and PEG-induced stress in 2010-11, in tissue culture for PEG-induced stress and using hydroponics for $\mathrm{NaCl}$-induced stress. The present study investigated plants under water-deficit stress, including the tolerance of soil-planted transgenic lines in pots. The studies used the same transgenic lines, but the sets of plants were different.

(7) Figure 3(b) was later reproduced as Figure 2(b) in Bala et al., in the Turkish Journal of Biology [5]. Though both show NptII amplification, the studies involve different transgenic plasmids. This was attributed to an inadvertent error and was corrected in May 2019 [6].

\section{Supplementary Materials}

The authors responded and provided some of the original figures and data, which are included as supplementary materials. (Supplementary Materials)

\section{References}

[1] T. D. Bhauso, T. Radhakrishnan, A. Kumar et al., "Overexpression of bacterial mtlD gene in peanut improves drought tolerance through accumulation of mannitol," The Scientific World Journal, vol. 2014, Article ID 125967, 10 pages, 2014.

[2] T. D. Bhauso, Transformation and Characterization of Transgenic Groundnut (Arachis hypogaea L.) with mtID. Gene for Abiotic Stress Tolerance, Junagadh Agricultural University, Junagadh, Gujarat, 2012, http://krishikosh.egranth.ac.in/ handle/1/5810027326.

[3] The Office of Research Integrity, U.S. Department of Health, Human Services, Statistical Forensics, https://ori.hhs.gov/ statistical-forensics-check.

[4] T. D. Bhauso, R. Thankappan, A. Kumar, G. P. Mishra, J. R. Dobaria, and M. Rajam, "Over-expression of bacterial mtlD gene confers enhanced tolerance to salt-stress and waterdeficit stress in transgenic peanut (Arachis hypogaea) through accumulation of mannitol," Australian Journal of Crop Science, vol. 8, no. 3, pp. 413-421, 2014.

[5] M. Bala, T. Radhakrishnan, A. Kumar, G. P. Mishra, J. R. Dobraia, and P. B. Kirti, "Overexpression of a fusion defensin gene from radish and fenugreek improves resistance against leaf spot diseases caused by Cercospora arachidicola and Phaeoisariopsis personata in peanut," Turkish Journal of Biology, vol. 40, pp. 139-149, 2016.

[6] M. Bala, T. Radhakrishnan, A. Kumar, G. P. Mishra, J. R. Dobraia, and P. B. Kirti, "Erratum: overexpression of a fusion defensin gene from radish and fenugreek improves resistance against leaf spot diseases caused by Cercospora arachidicola and Phaeoisariopsis personata in peanut," Turkish Journal of Biology, vol. 43, p. 154, 2019. 


\title{
Overexpression of Bacterial $\boldsymbol{m} t \boldsymbol{t D}$ Gene in Peanut Improves Drought Tolerance through Accumulation of Mannitol
}

\author{
Tengale Dipak Bhauso, ${ }^{1}$ Thankappan Radhakrishnan, \\ Abhay Kumar, ${ }^{1}$ Gyan Prakash Mishra, ${ }^{1}$ Jentilal Ramjibhai Dobaria, \\ Kirankumar Patel, ${ }^{1}$ and Manchikatla Venkat Rajam ${ }^{2}$ \\ ${ }^{1}$ Directorate of Groundnut Research, Post Box No. 5, Junagadh, Gujarat 362001, India \\ ${ }^{2}$ University of Delhi, Benito Juarez Road, New Delhi 110021, India \\ Correspondence should be addressed to Thankappan Radhakrishnan; radhakrishnan.nrcg@gmail.com
}

Received 29 July 2014; Revised 12 October 2014; Accepted 19 October 2014; Published 11 November 2014

Academic Editor: Anli Geng

Copyright @ 2014 Tengale Dipak Bhauso et al. This is an open access article distributed under the Creative Commons Attribution License, which permits unrestricted use, distribution, and reproduction in any medium, provided the original work is properly cited.

In the changing global environmental scenarios, water scarcity and recurrent drought impose huge reductions to the peanut (Arachis hypogaea L.) crop yield. In plants, osmotic adjustments associated with efficient free radical scavenging ability during abiotic stress are important components of stress tolerance mechanisms. Mannitol, a compatible solute, is known to scavenge hydroxyl radicals generated during various abiotic stresses, thereby conferring tolerance to water-deficit stress in many plant species. However, peanut plant is not known to synthesize mannitol. Therefore, bacterial mtlD gene coding for mannitol 1-phosphate dehydrogenase under the control of constitutive promoter CaMV35S was introduced and overexpressed in the peanut cv. GG 20 using Agrobacterium tumefaciens-mediated transformation. A total of eight independent transgenic events were confirmed at molecular level by PCR, Southern blotting, and RT-PCR. Transgenic lines had increased amount of mannitol and exhibited enhanced tolerance in response to water-deficit stress. Improved performance of the $m t l D$ transgenics was indicated by excised-leaf water loss assay and relative water content under water-deficit stress. Better performance of transgenics was due to the ability of the plants to synthesize mannitol. However, regulation of $m t l D$ gene expression in transgenic plants remains to be elucidated.

\section{Introduction}

Peanut (Arachis hypogaea L.) is one of the important grain crops widely grown in tropics and subtropics with the total production areas of $21-24 \mathrm{M}$ ha [1]. Peanut is generally grown under rain-fed conditions where drought is a major constraint limiting the productivity of peanut crop. Drought frequently occurs in the semiarid areas, which accounts for about $70 \%$ of the peanut growing area [2]. One of strategies to grow peanut crop in drought-prone environment is to develop peanut varieties tolerant to water-deficit stress [3]. Conventional plant breeding for drought-tolerant varieties is laborious and time consuming and commonly yields limited successes. Genetic engineering offers great potential for the improvement of peanut varieties tolerant to water-deficit stress [4].
Plants have evolved multiple mechanisms to survive drought stresses. Cellular dehydration is the common phenomenon under drought environment resulting in the loss of cell turgor [5]. In order to maintain cell turgor, plants usually accumulate low molecular weight compatible solutes [6]. In response to water deficit, there were enhanced productions of compatible solutes like polyols, amino acids, and tertiary and quaternary ammonium and sulfonium compounds. These compatible solutes play vital roles in protecting cells from cellular dehydration [6,7]. In general, accumulation of sugars, sugar alcohols, and proline $[8,9]$ in response to water deficit has been reported in many plant species.

It has been reported that mannitol, a kind of compatible solutes, is induced to accumulate in algae and higher plants during water deficit [10] and can be implicated in imparting drought tolerance $[8,11]$. However, peanut plant is not 

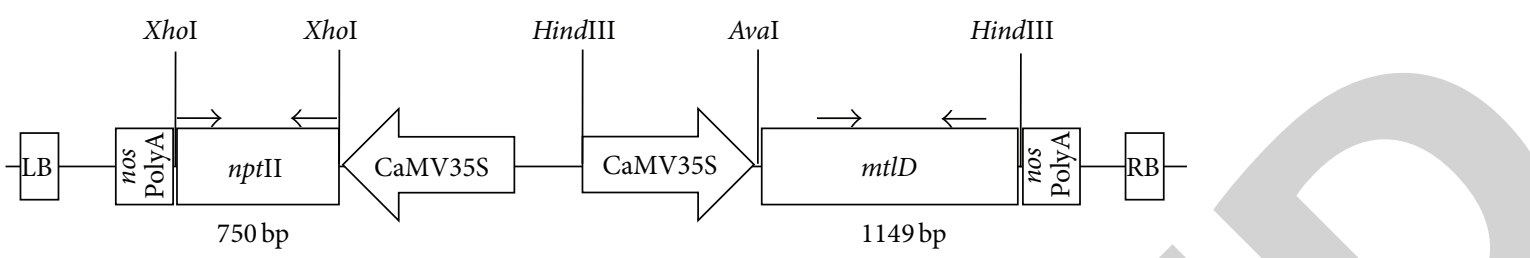

FIGURE 1: Schematic representation of the T-DNA region of pCAMBIA 1380 binary plasmid used for transformation of deembryonated cotyledons with Agrobacterium tumefaciens strain LBA 4404. The position of the primers used in PCR assays is shown by arrows on top of the $m t l D$ gene. LB, left T-DNA border sequence; RB, right border sequence; 35S, CaMV35S promoter; and mtlD, mannitol-1-phosphate dehydrogenase.

reported to synthesize mannitol. Mannitol is a six-carbon, noncyclic sugar-alcohol having its role in the coenzymes regulation, scavenging of free-radical, storage of energy, and osmoregulation [12]. The $m t l D$ is a bacterial gene that encodes mannitol 1-phosphate dehydrogenase. Transgenic plants carrying $m t l D$ convert mannitol 1-phosphate to mannitol via nonspecific phosphatases [13]. Overexpression of the genes involved in the biosynthesis of osmolytes, such as mannitol $[8,14]$, trehalose [15], and many more in various transgenic plants showed increased abiotic-stress tolerance.

The mtlD gene has been transferred to several crop species like wheat [16], eggplant [17], sorghum [18], and Maize [19] resulting in enhanced plant height, fresh and dry biomass weight, increase in salinity, and/or drought tolerance $[20,21]$. In these plants, biosynthesis and accumulation of mannitol increased, while its catabolism decreased under stress conditions $[3,22]$.

Mannitol is used as an additive in many processed foods and its overexpression is known to be a useful tool in enhancing crop resistance to drought [23]. Therefore, introducing novel genes encoding enzymes involved in biosynthesis of compatible solutes like mannitol could be a better alternative to conventional breeding to improve peanut varieties tolerant to drought stress [24]. An approach to improve abiotic stresstolerance by introducing $m t l D$ gene into peanut genome could be promising $[11,17]$.

In the present study, we report the successful introduction and overexpression of $m t l D$ gene cloned from Escherichia coli to the peanut cv. GG20, which is one of the most popular varieties of India, under the control of CaMV35S constitutive promoter. Overexpression of $m t l D$ gene has resulted in the synthesis of mannitol and conferred increased tolerance of drought stress in the transgenic peanut.

\section{Materials and Methods}

2.1. Plant Material and Culture Conditions. The seeds of peanut were surface sterilized with $70 \%$ ethanol for $1 \mathrm{~min}$ and $0.1 \%$ (w/v) $\mathrm{HgCl}_{2}$ for $3 \mathrm{~min}$ and rinsed three times with sterile distilled water. The testa was removed in a laminar air flow hood; embryos were removed; and excised cotyledons were used as explants. The cultures were done in modified MS medium [25] and maintained at $26 \pm 1^{\circ} \mathrm{C}, 16 \mathrm{~h}$ photoperiod with cool white fluorescent light of $42 \mu \mathrm{mol} \mathrm{m}^{-2} \mathrm{~s}^{-1}$ illumination for $15 \mathrm{~d}$ and then subcultured in medium containing $15 \mathrm{mg} / \mathrm{L}$ BAP.
2.2. Plasmid and Transformation Vector. The mtlD gene of E. coli which was originally isolated by Prof Hans J Bohnert (University of Illinois, USA) was used. The gene cassette had the 1149 bp coding region of $m t l D$, downstream of a CaMV35S promoter in the binary vector PCAMBIA 1380 containing a plant selectable marker gene, $n p t \mathrm{II}$ (Figure 1).

2.3. Plant Transformation, Selection, and Regeneration of Transformed Tissues. The excised cotyledon and immature leaf explants from mature presoaked seeds were transformed with A. tumefaciens strain LBA4404 harboring the binary plasmid pCAMBIA1380: $m t l D$ gene. The explants were infected with resuspended A. tumefaciens culture for $20 \mathrm{~min}$ at room temperature under continuous shaking and transferred on to cocultivation medium for 3 days at $26 \pm 1^{\circ} \mathrm{C}$ [25]. After transformation, the explants were rinsed 5-6 times with sterile water followed by a wash with cephataxime (Lupin, India) (200 mg/L), blotted to remove excess bacterial suspension, and cultured in the shoot inducing medium. To eliminate overgrowth of $A$. tumefaciens, the medium was also supplemented with cephataxime (Lupin, India) $(200 \mathrm{mg} / \mathrm{L})$.

The $1-2 \mathrm{~cm}$ long healthy shoots were transferred to MS basal media without hormones and grown for a week, before transferring to rooting medium. The shoots that survived the kanamycin selection were rooted on MS medium supplemented with $1 \mathrm{mg} \mathrm{L}^{-1} \mathrm{NAA}, 250 \mathrm{mg} \mathrm{L}^{-1}$ cefotaxime, and $100 \mathrm{mg} \mathrm{L}^{-1}$ kanamycin. The explants were subcultured at $15 \mathrm{~d}$ interval. The plantlets with well-developed roots were transferred to earthen pots for hardening and hardened plants were grown in a PII containment facility. The explants without Agrobacterium-infection were used as negative control.

2.4. Molecular Confirmation of Putative Transgenic Plants. PCR-analysis was done on the putative transgenics using gene-specific primers to pick up transgenics carrying the $m t l D$ and $n p t I I$ genes [26]. Genomic DNA was extracted from the young leaves of kanamycin-resistant and wild-type (WT) plants using the DNAzol kit (Molecular Research Center, Inc.). The plasmid DNA was also amplified with respective primers as positive control. The PCR reaction $(20 \mu \mathrm{L})$ is comprised of $2 \mu \mathrm{L} 10 \mathrm{x}$ PCR buffer (Fermentas), $1 \mu \mathrm{L}$ genomic DNA (100 ng), $1.6 \mu \mathrm{L}$ dNTP mix $(2 \mathrm{mM}), 1 \mu \mathrm{L}$ forward and reverse primers (25 pM each), and $1 \mathrm{U}$ Taq DNA polymerase (Fermentas). 
The pair of primers for the detection of the mtlD coding region is $m t l$ D-Fwd: $5^{\prime}$-GGGCAGGTGAAACGTAAAGA$3^{\prime}$ and $m t l \mathrm{D}$-Rev: $5^{\prime}$-CAGTTTACGCAGTGGCTGAC- $3^{\prime}$ (annealing temperature $60^{\circ} \mathrm{C}$; product size $600 \mathrm{bp}$ ) and, for the $n p t I I$ gene, $n p t I I-F w d: 5^{\prime}$-GAGGCTATTCGGCTATGACTG- $3^{\prime}$ and nptII-Rev: $5^{\prime}$-ATCGGGAGCGGCGATACGTA $-3^{\prime}$ (annealing temperature $56^{\circ} \mathrm{C}$; product size $750 \mathrm{bp}$ ).

PCR reactions were set up with the following thermal profile: $94^{\circ} \mathrm{C}$ for $4 \mathrm{~min}$, followed by 35 cycles of $94^{\circ} \mathrm{C}$ for $1 \mathrm{~min}, 60^{\circ} \mathrm{C}$ or $56^{\circ} \mathrm{C}$ (for $m t l \mathrm{D}$ and $n p t \mathrm{II}$, resp.) for $45 \mathrm{~s}$, and $72^{\circ} \mathrm{C}$ for $1 \mathrm{~min}$ and final extension at $72^{\circ} \mathrm{C}$ for $7 \mathrm{~min}$. The amplified product was resolved on $1.2 \%$ agarose gel, visualized by Ethidium bromide staining, and documented using a Fuji FLA5200 imaging system.

2.5. RNA Isolation and RT-PCR. Total mRNA was isolated from eight lines obtained from independent transformation events (MTD1-8 in $\mathrm{T}_{2}$ generation) and the WT using RNA extraction kit (Qiagen) and subjected to RNase-free DNase I (Fermentas) digestion and purification [26]. The RNA was quantified using ND-1000 spectrophotometer (NanoDrop Technologies Inc., USA). Equal amount of RNA from each sample was used for the two-step RT-PCR reaction. The first-strand of cDNA was synthesized from $1 \mu \mathrm{g}$ RNA per sample using first strand cDNA synthesis kit (Fermentas) and the product obtained was further used for second-strand amplification using gene specific primers via PCR.

2.6. Segregation Analysis. Selected $\mathrm{T}_{0}$ plants with sufficient number of seeds were selected for segregation analysis [26]. The $T_{1}$ progeny of the five lines was grown in pots under controlled conditions in a PII containment facility. The plantlets at 2-4-leaf stage were used for PCR analysis using gene-specific primers to score the amplicons. The $\chi^{2}$ test was conducted in the progenies from all the events on the basis of expected and observed frequencies.

2.7. Southern Blot Analysis. Genomic DNA $(30 \mu \mathrm{g})$ of transgenic and WT plants was individually digested with EcoRI, separated on $0.8 \%$ agarose gel, and then transferred to Biodyne plus $(0.45 \mu \mathrm{m})$ nylon membrane (PALL Life Sciences) using alkaline transfer buffer $(0.4 \mathrm{~N} \mathrm{NaOH}$ and $1 \mathrm{M} \mathrm{NaCl})$. The $m t l D$ probe (285-bp), labelled with thermostable alkaline phosphatase, using alkaphos direct labelling kit (Amersham, GE Healthcare, UK), was used for hybridization. Hybridization was carried out overnight at $55^{\circ} \mathrm{C}$ in hybridization buffer (Amersham, GE Healthcare, UK) and membrane was washed (at $55^{\circ} \mathrm{C}$ for $15 \mathrm{~min}$ ) first in primary wash buffer $(25 \mathrm{~mL}$ ) and then in secondary wash buffer at room temperature. Hybridized membrane was detected by using CDP-star chemiluminescent as substrate and signals were visualised on Amersham Hyperfilm ECL after $1 \mathrm{~h}$.

\section{Water Stress Experiments}

The $45 \mathrm{~d}$ old $m t l D$ transgenic plants in $\mathrm{T}_{2}$ generation and WT lines which were grown under PII containment facility were used for water-deficit stress tolerance studies after withholding the irrigation for 24 days. All the eight independent transgenic lines, namely, MTD1-8 along with WT, were evaluated for the following parameters.

3.1. Estimation of Mannitol Level. Mannitol was extracted from the leaves (WT and $\mathrm{T}_{2}$ transgenic) and quantified by binary gradient High Performance Liquid Chromatography (Shimadzu LC 10 series) as described by Tarczynski et al. [14]. For separation, $10 \mu \mathrm{L}$ sample was injected per run (operated at $\left.1 \mathrm{~mL} \mathrm{~min}^{-1}\right)$ with acetonitrile: water $(80: 20)$ as mobile phase using $5 \mu$ Luna, $\mathrm{NH}_{2} 100 \AA$ column (at $40^{\circ} \mathrm{C}$ ) and $\mathrm{RI}$ detector was used for detection. Mannitol (SRL; $10 \mathrm{mg} \mathrm{L}^{-1}$ ) was used to develop the calibration curve to optimize the mannitol separation by diluting it to four concentration levels of $1 \mathrm{mg} \mathrm{L}^{-1}, 2 \mathrm{mg} \mathrm{L}^{-1}, 5 \mathrm{mg} \mathrm{L}^{-1}$, and $10 \mathrm{mg} \mathrm{L}^{-1}$. The concentration value is calculated from the area/height of the peaks on the calibration curve [8].

3.2. Excised-Leaf Water Loss Assay. The assay as proposed by Pierce and Raschke [27] was used with minor modification. First fully expanded leaves on the main stem from transgenic and WT plants (03 leaves each) grown under well watered conditions were excised early in the morning and placed in abaxial side up in open petri dishes. The leaves were then exposed to a light intensity of $538 \mu \mathrm{mol} \mathrm{m}^{-2} \mathrm{~s}^{-1}$ (incandescent) for $8 \mathrm{~h}$ in a growth chamber. The loss in weight was recorded for $8 \mathrm{~h}$ at $60 \mathrm{~min}$ interval. After incubation, the percentage loss in fresh weight over the unincubated control was calculated.

3.3. Relative Water Content (RWC). The fresh leaf discs were used to measure RWC as per Barrs and Weatherley [28]. Initial fresh weights $(\mathrm{FW})$ were measured prior to floating in petri-plates containing water $(8 \mathrm{~h})$ for hydration and were weighed again to measure the turgid weight (TW). It is then dried in a hot air oven $\left(80^{\circ} \mathrm{C}\right.$ for $\left.72 \mathrm{~h}\right)$ and weighed till a consistent dry weight (DW) was obtained. RWC was calculated as RWC $=[(\mathrm{FW}-\mathrm{DW}) /(\mathrm{TW}-\mathrm{DW})] \times 100$.

3.4. Statistical Analysis. The experiments on mannitol content, excised-leaf water loss assay, and RWC were set up in completely randomized design (CRD) in three replications. The significance of the treatment effects was determined by one-way ANOVA of SPSS 11.0 (Statistical Package For Social Sciences, SPSS Inc., Illinois) at 5\% probability level using Tukey test. The goodness of fit of the observed segregation ratio for the $m t l D$ transgene in $\mathrm{T}_{1}$ generation was tested against the Mendelian segregation ratio (3:1) using the chisquare $\left(\chi^{2}\right)$ test.

\section{Results}

4.1. Tissue Culture and Transformation. In vitro regeneration from the excised cotyledons of peanut resulted in direct shoot initiation after 100-105 d. Transformation efficiency was evaluated as the number of independent transgenic lines with respect to the initial number of explants cultured. In 


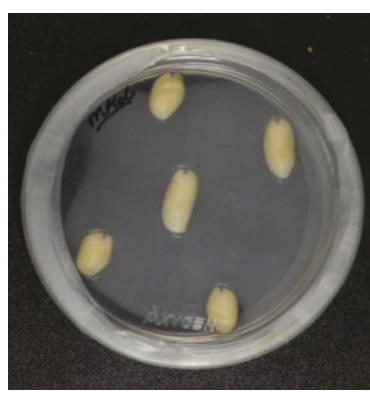

(a)

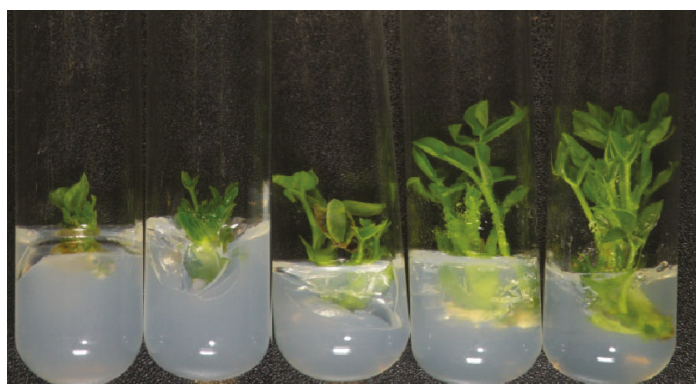

(d)

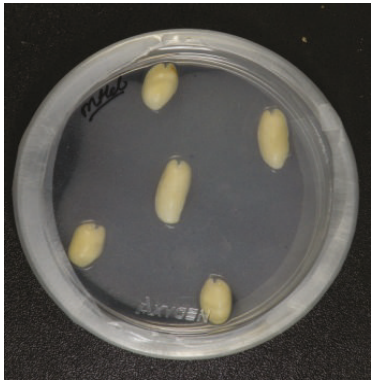

(b)

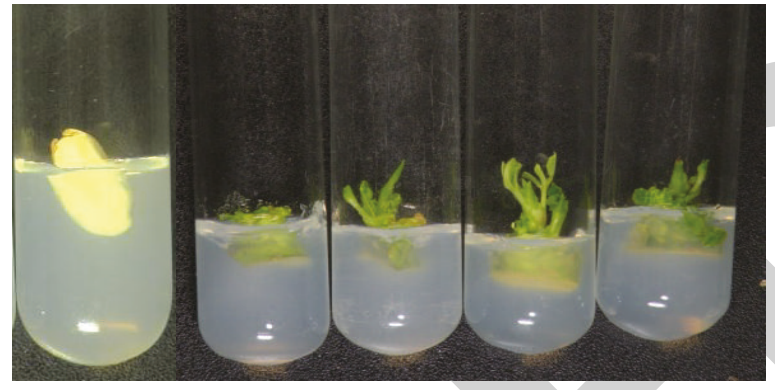

(c)
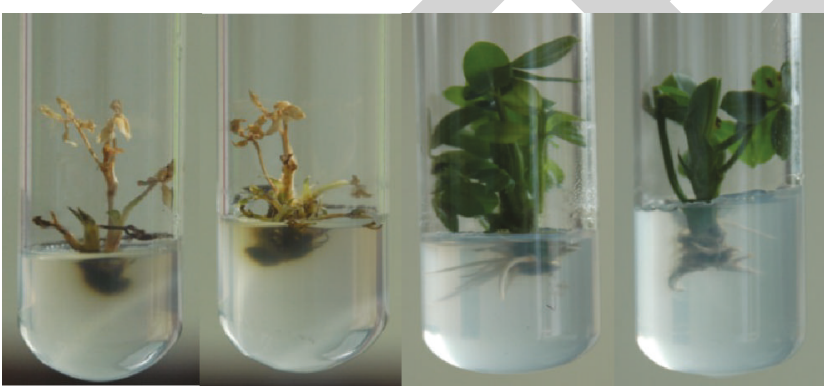

(e)

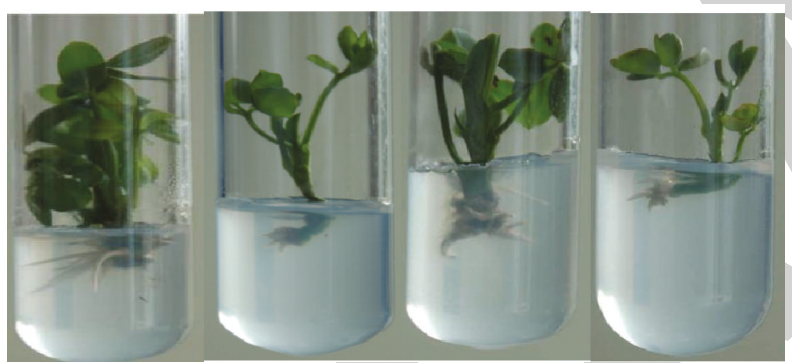

(f)

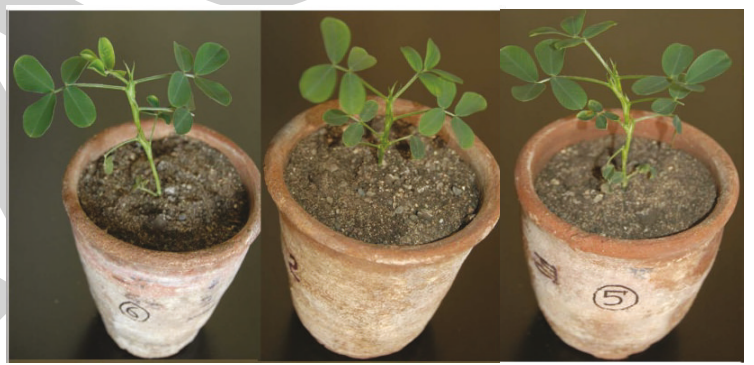

(g)

FIGURE 2: Genetic transformation and regeneration of peanut from deembryonated cotyledons. (a)-(b) Deembryonated cotyledons cocultured with Agrobacterium strain LBA4404; (c) shoot buds initiating from cocultured deembryonated cotyledons; (d) sequential regeneration process of shoots from deembryonated cotyledon explant in various concentration media; (e) transformed (green) and nontransformed shoots (yellow) in Kanamycin selection media; (f) transformed healthy shoots in Kanamycin selection media containing NAA; and (g) transformed groundnut plant with well-developed shoots transferred in pots for hardening.

TABLE 1: Genetic transformation and regeneration of peanut explants from the cultivar GG 20.

\begin{tabular}{lccccc}
\hline $\begin{array}{l}\text { Number of } \\
\text { cocultivations }\end{array}$ & $\begin{array}{c}\text { Total explants } \\
\text { cocultured }\end{array}$ & Shoots produced & $\begin{array}{c}\text { Shoots passed } \\
\text { antibiotic selection }\end{array}$ & $\begin{array}{c}\text { Shoots produced } \\
\text { roots }\end{array}$ & $\begin{array}{c}\text { Plantlets hardened } \\
\text { and survived in } \\
\text { glasshouse }\end{array}$ \\
\hline 15 & 1096 & 865 & $532(61)^{*}$ & $431(81)$ & $193(45)$ \\
\hline
\end{tabular}

${ }^{*}$ Values in parenthesis are percentage.

the present investigation, 1096 explants, which are cultured in 15 batches, could produce 865 shoots. After 6 weeks of culture on the selection medium, $532(61 \%)$ shoots survived in selection medium of which 193 (45\%) shoots survived under PII containment facility (Figures 2(a) to 2(g)). Finally, only 10 shoots $(5.18 \%)$ were found to be PCR positive when screened with transgene specific primers (Table 1). Though the regeneration frequency recorded was quite high, the number of confirmed independent transgenic events finally obtained was relatively low. Similar trend has been observed by Kumar et al. [29] and Tiwari et al. [30]. All transgenic lines appeared normal in morphology and development.

4.2. Integration of Transgene in Host Genome. Kanamycinresistant $\mathrm{T}_{0}$ transgenic plants were subjected to PCR analysis using transgene specific primers so as to confirm the integration of the transgenes, namely, $m t l D$ and $n p t I I$. PCR analysis detected the presence of $600 \mathrm{bp}$ amplicon of the $m t l D$ and $750 \mathrm{bp}$ of $n p t \mathrm{II}$ (Figures $3(\mathrm{a})$ and 3(b)) genes, confirming the presence of the transgenes. Southern hybridization was 


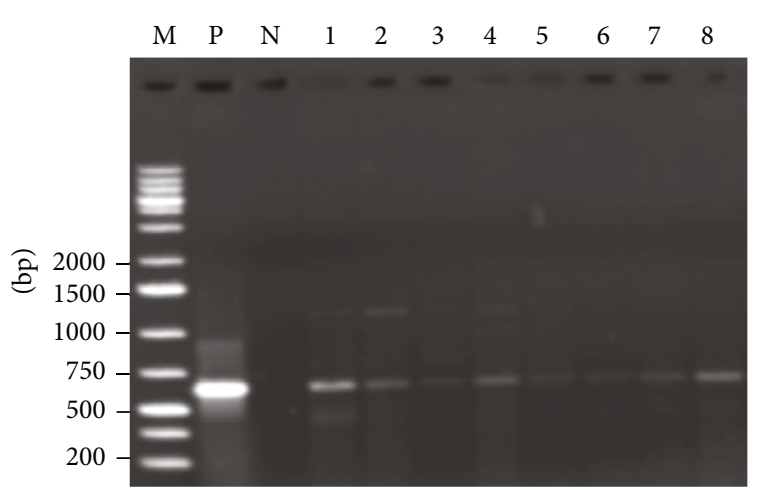

(a)

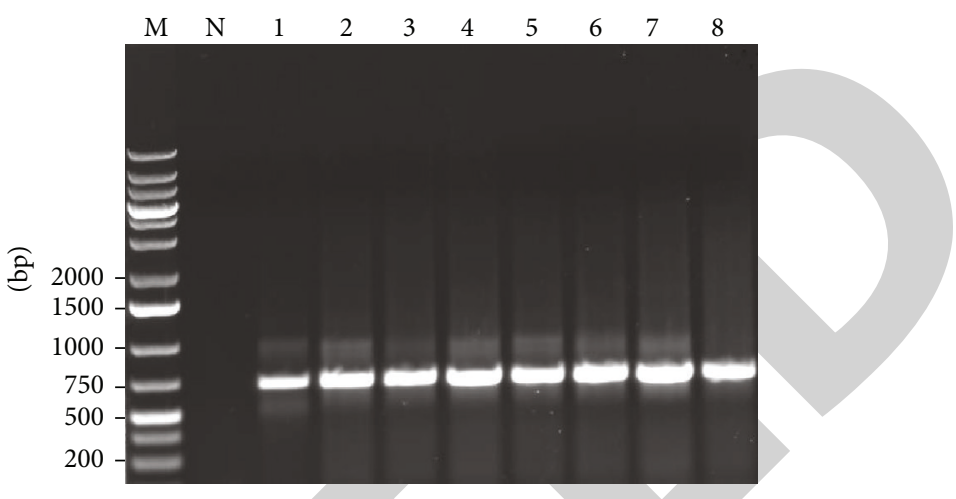

(b)

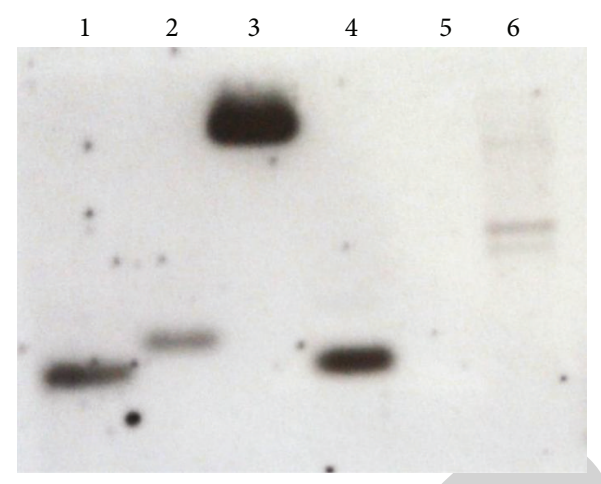

(c)

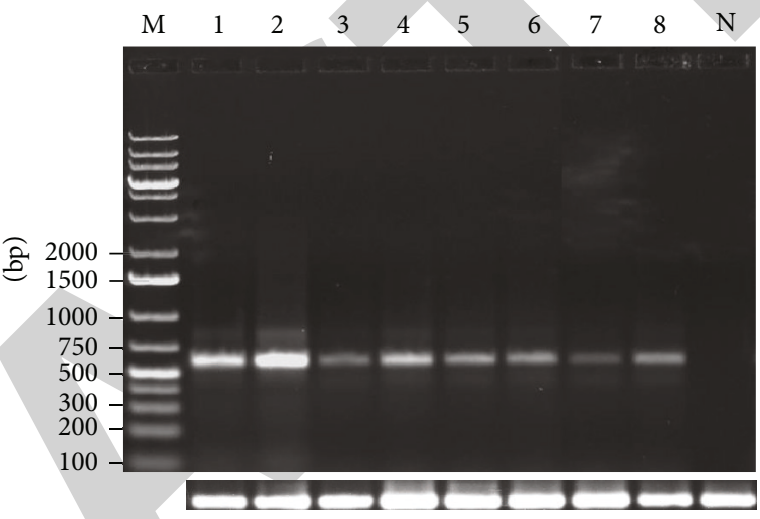

(d)

FIGURE 3: Molecular characterization of $m t l D$ peanut transformants. (a) PCR amplification using $m t l D$ gene-specific primers (expected size $600 \mathrm{bp}$ ); (b) PCR amplification of transformants using $n p t \mathrm{II}$ gene specific primers (expected size 750 bp), where lane N: negative control; lane P: positive control (pCAMBIA1380 plasmid DNA); and lanes 1-8: transgenic lines (MTD1 to MTD8); (c) Southern blot analysis of transgenic $\left(\mathrm{T}_{0}\right)$ and nontransformed peanut lines. Where lanes 1-4: DNA from transgenic lines, lane 5: DNA from nontransformed line (cv. GG 20, -ve control), and lane 6: plasmid DNA (+ve control); (d) detection of $m$ tlD gene transcription in transgenic plants using RT-PCR. Lane N = nontransformed line; lanes 1-8 = transgenic lines (MTD1 to MTD8), bottom row: 18SrRNA as internal control.

also carried out with $\mathrm{T}_{0}$ transgenic plants to check the integration and copy number of the transgene in putative transgenic plants. All the putative transgenic plants tested positive having single copy number of transgene, while the untransformed plant tested negative (Figure 3(c)).

4.3. Expression of the Transgene. RT-PCR analysis was performed on the PCR positive plants to confirm the expression of the $m t l D$ transcript in transgenic $\left(\mathrm{T}_{0}\right)$ plants. $18 \mathrm{~S}$ rRNA was used as an internal reference to normalize the initial cDNA content among samples. The result showed that the transgenic lines have expressed the $m t l D$ gene at transcript level whereas no amplification was observed in untransformed plants (Figure 3(d)). There were some differences in the intensity of the RT-PCR bands. The transgenic lines MTD1, 2, and 8 showed higher mRNA titers in comparison to other lines.

4.4. Segregation Analysis. All the selected eight $\mathrm{T}_{0}$ plants were found fertile and produced seeds. The progenies of these $m t l D$ positive transgenics were further tested for the segregation by chi-square analysis. The segregation pattern for $m t l D$ gene in $\mathrm{T}_{1}$ plants showed a $3: 1$ ratio, expected for single dominant gene inheritance, for six out of eight transformed lines studied (Table 2). Similar segregation pattern of transgene was also reported by Cheng et al. [31] and Tiwari et al. [30].

\subsection{Characterization of Transgenic Peanut}

4.5.1. Accumulation of Mannitol. All the transgenic lines expressed $m t l D$ transgene under PII containment facility. Mannitol content recorded under well-watered and waterdeficit stress condition in transgenic lines ranged from 1.81$2.98 \mu \mathrm{g} \mathrm{g}^{-1}$ to $3.02-4.74 \mu \mathrm{g} \mathrm{g}^{-1} \mathrm{FW}$ of tissue, respectively (Table 3). Under water-deficit stress, different transgenic lines had significantly different levels of mannitol suggesting multiple mechanisms controlling the activity of the enzyme encoded by the transgene and the level of gene expression [32].

4.5.2. Excised-Leaf Water Loss Assay. After $4 \mathrm{~h}$ under dehydration conditions, the detached leaves of the mtlD overexpressing peanut plants lost less water than the detached leaves of the WT plants (Figures 4 and 5). This may be due to the 
TABLE 2: Segregation analysis of defensin gene in selfed progenies $\left(\mathrm{T}_{1}\right)$ derived from $m t l \mathrm{D}$ transgenic peanut plants.

\begin{tabular}{|c|c|c|c|c|c|c|c|}
\hline \multirow{2}{*}{ Transformed groundnut lines } & \multicolumn{3}{|c|}{ Number of plants } & \multirow{2}{*}{ Observed ratio } & \multirow{2}{*}{ Test ratio } & \multirow{2}{*}{$\chi^{2}$} & \multirow{2}{*}{$P$ value } \\
\hline & Total & $m t l D+$ & $m t l D-$ & & & & \\
\hline MTD1 & 54 & 41 & 13 & $3.15: 1$ & $3: 1$ & 0.025 & 0.8744 \\
\hline MTD2 & 79 & 59 & 20 & $2.95: 1$ & $3: 1$ & 0.004 & 0.9482 \\
\hline MTD3 & 82 & 62 & 20 & $3.1: 1$ & $3: 1$ & 0.016 & 0.8993 \\
\hline MTD4 & 31 & 22 & 9 & $2.44: 1$ & $3: 1$ & 0.269 & 0.6041 \\
\hline MTD5 & 16 & 10 & 6 & $1.66: 1$ & $3: 1$ & 1.333 & 0.2482 \\
\hline MTD6 & 10 & 7 & 3 & $2.33: 1$ & $3: 1$ & 0.133 & 0.7153 \\
\hline MTD7 & 20 & 15 & 5 & $3: 1$ & $3: 1$ & 0.000 & 1.000 \\
\hline MTD8 & 24 & 16 & 8 & $2: 1$ & $3: 1$ & 0.889 & 0.3457 \\
\hline
\end{tabular}

$P=0.05, \mathrm{df}=1$.

TABLE 3: Effect of imposing water-deficit stress on 45-day-old plants ( T and WT) after 24 days of stress imposition on mannitol content.

\begin{tabular}{lcc}
\hline Line No. & \multicolumn{2}{c}{ Mannitol content $(\mu \mathrm{g} / \mathrm{g}$ FW $)$} \\
& Water-deficit stress & Well watered \\
\hline MTD1 & $3.02 \pm 0.31^{\mathrm{d}^{\mathrm{z}}}$ & $2.25 \pm 0.29^{\mathrm{ab}}$ \\
MTD2 & $3.30 \pm 0.42^{\mathrm{cd}}$ & $1.81 \pm 0.22^{\mathrm{b}}$ \\
MTD3 & $4.74 \pm 0.41^{\mathrm{a}}$ & $2.98 \pm 0.38^{\mathrm{a}}$ \\
MTD4 & $3.72 \pm 0.10^{\mathrm{bcd}}$ & $2.83 \pm 0.16^{\mathrm{a}}$ \\
MTD5 & $4.65 \pm 0.33^{\mathrm{a}}$ & $2.74 \pm 0.29^{\mathrm{a}}$ \\
MTD6 & $4.26 \pm 0.22^{\mathrm{ab}}$ & $2.84 \pm 0.14^{\mathrm{a}}$ \\
MTD7 & $3.58 \pm 0.17^{\mathrm{bc}}$ & $2.71 \pm 0.29^{\mathrm{a}}$ \\
MTD8 & $4.12 \pm 0.39^{\mathrm{abc}}$ & $2.73 \pm 0.29^{\mathrm{a}}$ \\
GG 20 (WT) & $\mathrm{ND}$ & $\mathrm{ND}$ \\
\hline LSD & 0.90 & 0.80 \\
\hline
\end{tabular}

The data are mean of three replicates \pm SE; ND: not detected; ${ }^{\mathrm{z}}$ means followed by the same lower case letters within a column are not significantly different $(P \leq 0.05)$.

greater mannitol accumulation in transgenic plants than in WT.

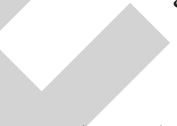

4.5.3. Relative Water Content (RWC). Under both wellwatered and water-deficit stress, all the transgenics had significantly higher RWC over WT. Transgenics exhibited less reduction in the RWC than WT under water-deficit stress which was indicative of greater tolerance for water-deficit stress (Figure 6).

\section{Discussion}

Mannitol accumulation in $m t l D$ transgenics is expected to confer a range of biotic and abiotic-stress tolerance $[8,11,33]$. Although mannitol is synthesized in various plant species, it is absent in peanut. Under stress, 1.31- to 1.82-fold increase in mannitol content was observed in different transgenics compared to the nonstressed transgenics (Table 3 ). When compared to the nonstressed plants, 3-10 folds of mannitol accumulation in transgenics egg plants have been reported by
Prabhavathi et al. [17]. An increased accumulation of mannitol in the transgenic peanut lines indicates their tolerance capacity against drought-stress [33].

In earlier reports, transgenics with different levels of mannitol in their tissues have been shown to be tolerant to different type of abiotic stresses $[3,11]$. The results of Nagabhyru et al. [34] also suggest that an endophytic fungus Neotyphodium coenophialum assists in imparting drought tolerance in tall fescue, by the accumulation of many compatible solutes like proline and mannitol. This supports that the level of mannitol accumulated in the tissues may act as osmoprotectant and protect the cells from free radicals and, in addition, induces several stress tolerance pathways which result in increase in their abiotic stress tolerance ability $[8,12,18,35]$.

The dynamic loss in fresh weight of excised leaves by desiccation was used as a quick and convenient method of estimating the degree of water stress $[36,37]$. Differences in the capacity to conserve water in different transgenic lines were observed when drought stress was imposed on transgenics. Transgenic line MTD8 presented higher capacity to conserve their water over other transgenic lines (Figures 4 and 5). Under well-watered conditions, however, no significant differences were observed in capacity to conserve their water among these genotypes. Similar results were recorded by other workers for different transgenics when evaluated using excised-leaf water loss assay $[36,37]$.

RWC is a physiological index related to the uptake of water by the roots, water loss by transpiration, and closure of stomata. We measured the leaf RWC since it is considered a suitable indicator for plant tissue water retention capacity and acts as an appropriate parameter to measure water status and osmotic adjustments of plants under abiotic stresses [11, 38]. Also, when the leaf RWC is reduced below some critical threshold (e.g., below $0.3 \mathrm{~g} \mathrm{H}_{2} \mathrm{O} \mathrm{g}^{-1} \mathrm{DW}$ ), there is insufficient water for preferential hydrations [39]. Transgenics peanut expressing $m t l D$ gene displayed less reduction in the RWC than WT under water-deficit stress (Figure 6), supporting the reports of Karakas et al. [20] in tobacco, Abebe et al. [3] in wheat, Hema et al. [35] in finger millet, and Rai et al. [38] in tomato indicating that transgenics plants could effectively retain more water-content under drought-stress, with minimum reduction in RWC. 


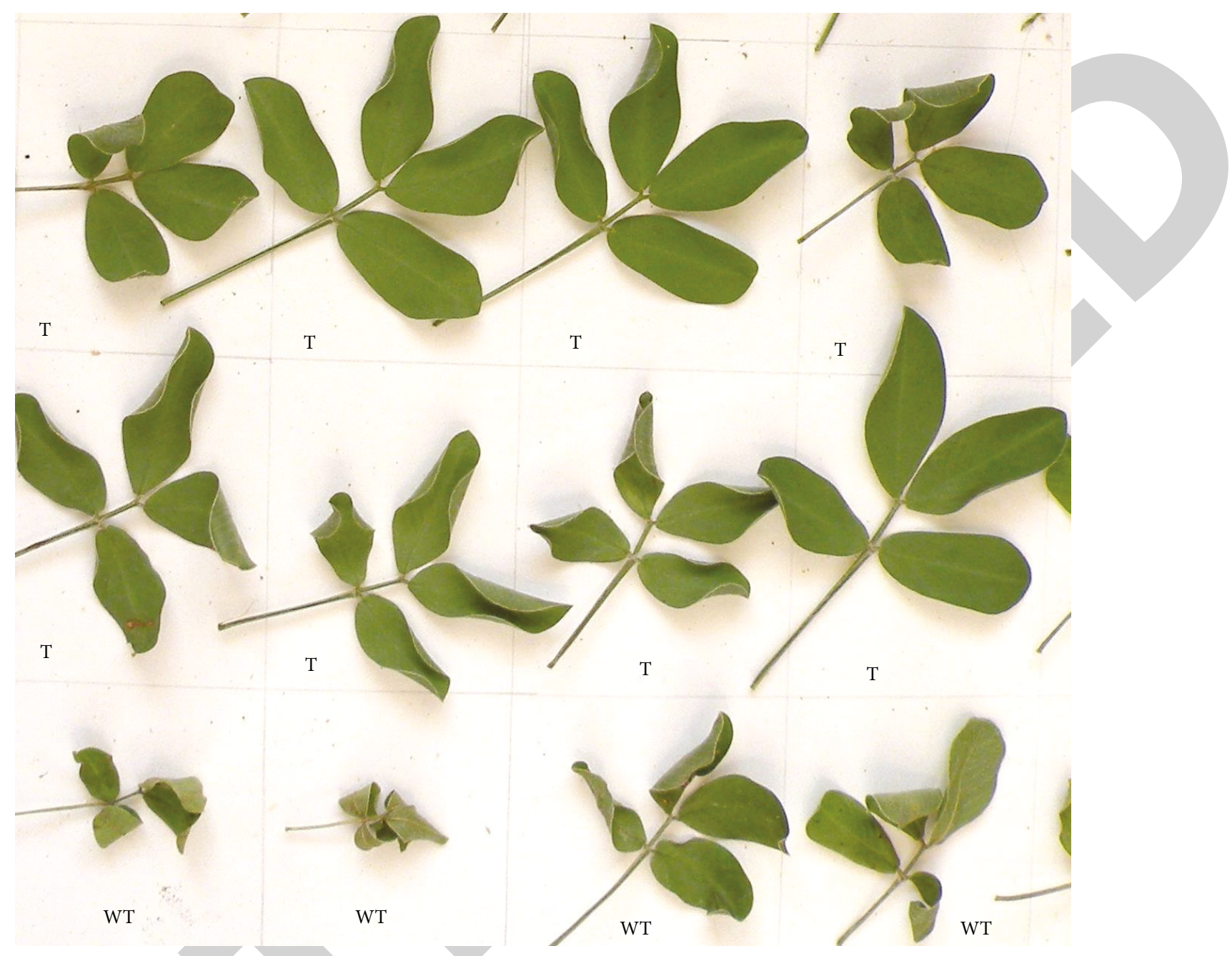

FIGURE 4: Representative picture of excised-leaf water loss assay where detached leaves of transgenic (T) plants showed less water loss in a given time-span over wild-type (WT) plants.

The present results agree with Nguyen et al. [19] work in transgenic maize where $H V A 1$ and $m t l D$ genes resulted in improved total biomass and showed greater water use efficiency under drought conditions. The exact mechanism of $m t l D$ induced regulation, responsible for improved physiobiochemical and growth-parameters under various stresses, is yet to be deciphered. Further analysis is required to study the expression pattern of $m t l D$ gene when used with stress inducible promoter for the creation of transgenic peanut.

In the era of global warming, drought can be a devastating problem, leaving peanut farmers with very low yields and less farm incomes. Our results established that the overexpression of $m t l D$ using transgenic approach confers water-deficit stress tolerance in peanut crop by way of accumulating the mannitol. In addition to acting as an osmoregulator, sugar alcohols also maintain the enzyme-activity in a cell by maintaining the surface bound water of protein and keeping its conformation in solution [40] and displayed antioxidant activities [41] leading to increased tolerance to water deficit stress in transgenic peanut.
Although, many transgenic peanut lines have been developed across the world by different group of researchers with various degrees of improved abiotic stress tolerance but, till-date, no commercial varieties are released $[42,43]$. Therefore, multiyear, multilocation field testing of the developed transgenic lines is required to further confirm the drought tolerance under actual field conditions [19]. Subsequently, the $m t l D$ transgenic peanut lines, when released, are expected to improve farmer's profits in the regions of the world where unexpected and recurrent drought is one of the main factors limiting the peanut productivity. Besides, it can also be utilized as valuable prebreeding resource in the peanut improvement programme on abiotic stresses.

\section{Conflict of Interests}

The authors declare that there is no conflict of interests regarding to the publication of this paper. 


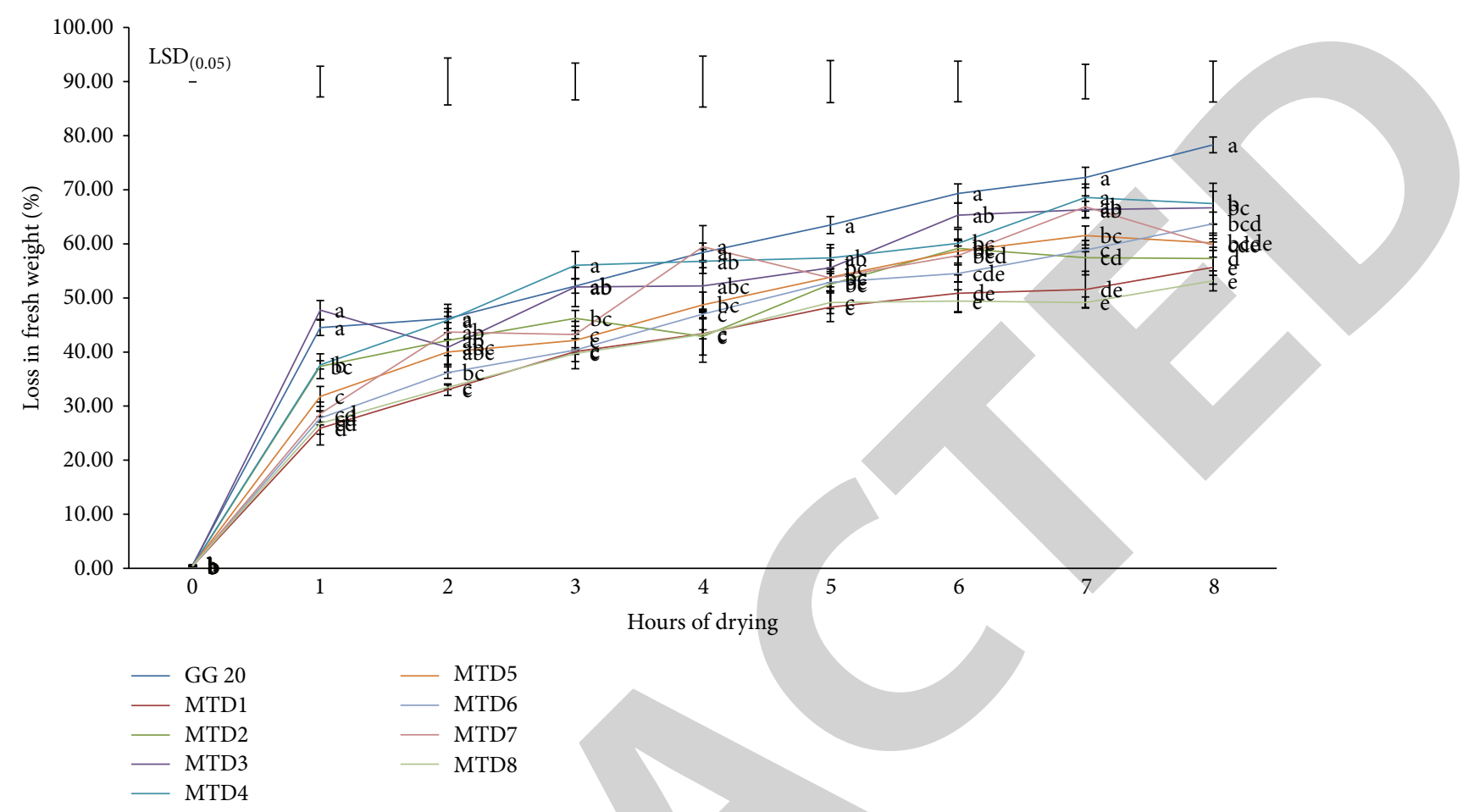

FIGURE 5: Excised-leaves water loss assay shows significantly higher water loss in WT whereas reduced water-loss was found in $m t l D$ transgenics. Data are average $\pm \mathrm{SE}$ from three independent experiments; bars on the top represent the $\mathrm{LSD}_{0.05}$. Bars having same lower-case letters within treatments are not significantly different $(P \leq 0.05)$.

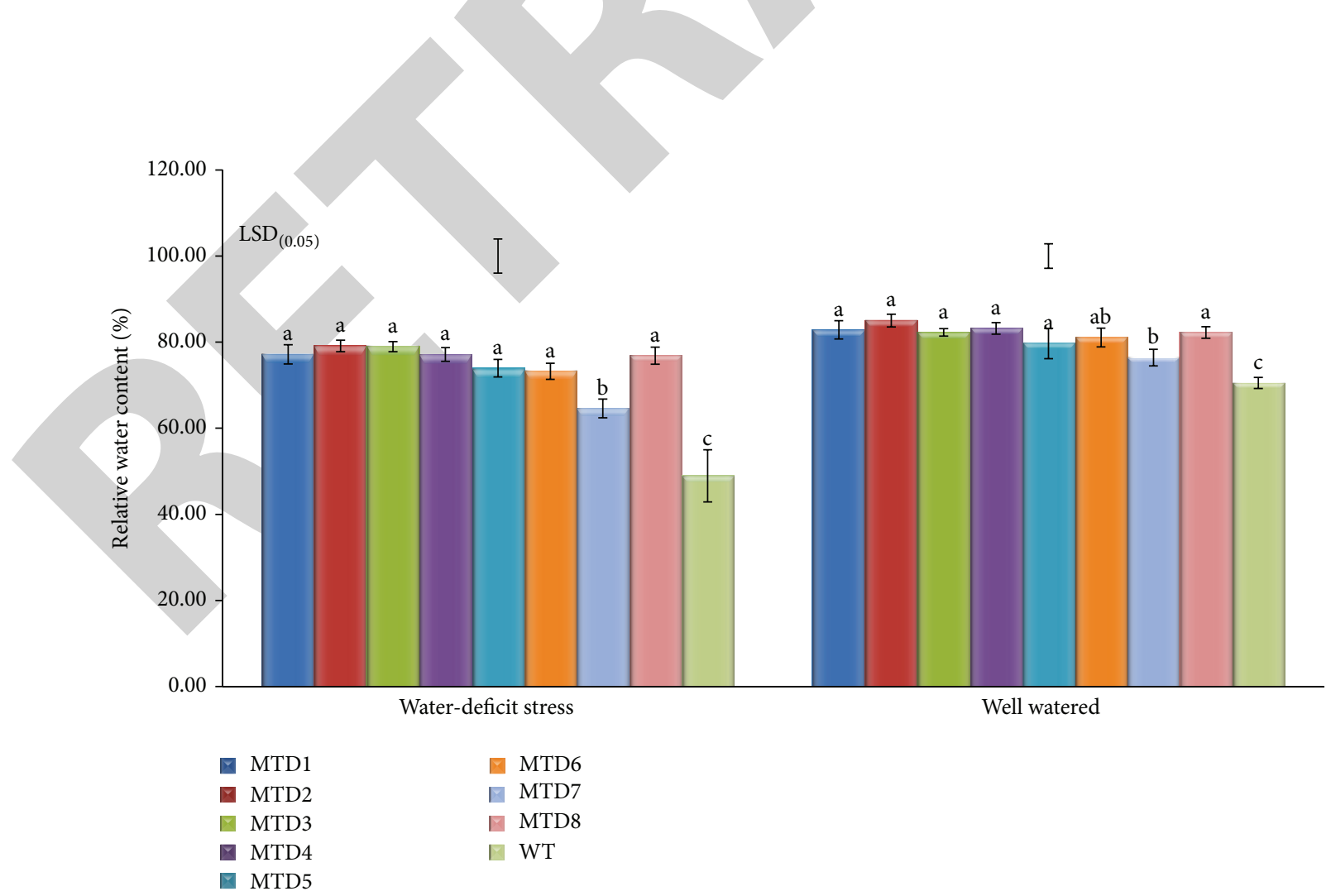

FIGURE 6: Effect of imposing water-deficit stress at full-growth stage in transgenic lines (MTDs) and WT (GG 20) on RWC content. Values are mean of three replicates and bars indicate $\pm \mathrm{SE}$; bars on the top represent the $\mathrm{LSD}_{0.05}$. Bars having same lower-case letters within treatments are not significantly different $(P \leq 0.05)$. 


\section{Acknowledgments}

The authors thank Professor Hans J. Bohnert, University of Illinois, USA, for providing $m t l D$ gene construct. This research work was supported by Indian Council of Agricultural Research, New Delhi, India.

\section{References}

[1] USDA, 2014, http://www.fas.usda.gov/psdonline/.

[2] T. Y. Reddy, V. R. Reddy, and V. Anbumozhi, "Physiological responses of groundnut (Arachis hypogea L.) to drought stress and its amelioration: a critical review," Plant Growth Regulation, vol. 41, no. 1, pp. 75-88, 2003.

[3] T. Abebe, A. C. Guenzi, B. Martin, and J. C. Cushman, "Tolerance of mannitol-accumulating transgenic wheat to water stress and salinity," Plant Physiology, vol. 131, no. 4, pp. 17481755, 2003.

[4] K. Ravi, V. Vadez, S. Isobe et al., "Identification of several small main-effect QTLs and a large number of epistatic QTLs for drought tolerance related traits in groundnut (Arachis hypogaea L.)," Theoretical and Applied Genetics, vol. 122, no. 6, pp. 11191132, 2011.

[5] E. Blumwald, "Sodium transport and salt tolerance in plants," Current Opinion in Cell Biology, vol. 12, no. 4, pp. 431-434, 2000.

[6] W. Wang, B. Vinocur, and A. Altman, "Plant responses to drought, salinity and extreme temperatures: towards genetic engineering for stress tolerance," Planta, vol. 218, no. 1, pp. 1-14, 2003.

[7] A. M. Almeida, L. A. Cardoso, D. M. Santos, J. M. Torné, and P. S. Fevereiro, "Trehalose and its applications in plant biotechnology," In Vitro Cellular \& Developmental BiologyPlant, vol. 43, no. 3, pp. 167-177, 2007.

[8] T. D. Bhauso, R. Thankappan, A. Kumar, G. P. Mishra, J. R. Dobaria, and M. Rajam, "Over-expression of bacterial mtlD gene confers enhanced tolerance to salt-stress and waterdeficit stress in transgenic peanut (Arachis hypogaea) through accumulation of mannitol," Australian Journal of Crop Science, vol. 8, no. 3, pp. 413-421, 2014.

[9] H. Bandurska and W. Jóźwiak, "A comparison of the effects of drought on proline accumulation and peroxidases activity in leaves of Festuca rubra L. and Lolium perenne L," Acta Societatis Botanicorum Poloniae, vol. 79, no. 2, pp. 111-116, 2010.

[10] Y. Wang, J. Ying, M. Kuzma et al., "Molecular tailoring of farnesylation for plant drought tolerance and yield protection," Plant Journal, vol. 43, no. 3, pp. 413-424, 2005.

[11] N. Khare, D. Goyary, N. K. Singh et al., "Transgenic tomato cv. Pusa Uphar expressing a bacterial mannitol-1-phosphate dehydrogenase gene confers abiotic stress tolerance," Plant Cell, Tissue and Organ Culture, vol. 103, no. 2, pp. 267-277, 2010.

[12] J. M. H. Stoop, J. D. Williamson, and D. M. Pharr, "Mannitol metabolism in plants: a method for coping with stress," Trends in Plant Science, vol. 1, no. 5, pp. 139-144, 1996.

[13] B. Rathinasabapathi, "Metabolic engineering for stress tolerance: installing osmoprotectant synthesis pathways," Annals of Botany, vol. 86, no. 4, pp. 709-716, 2000.

[14] M. C. Tarczynski, R. G. Jensen, and H. J. Bohnert, "Expression of a bacterial mtlD gene in transgenic tobacco leads to production and accumulation of mannitol," Proceedings of the National Academy of Sciences of the United States of America, vol. 89, no. 7, pp. 2600-2604, 1992.
[15] A. K. Garg, J. K. Kim, T. G. Owens et al., "Trehalose accumulation in rice plants confers high tolerance levels to different abiotic stresses," Proceedings of the National Academy of Sciences of the United States of America, vol. 99, pp. 15898-15903, 2002.

[16] A. M. Ramadan, H. F. Eissa, S. E. Hassanein et al., "Increased salt stress tolerance and modified sugar content of bread wheat stably expressing the mtlD gene," Life Science Journal, vol. 10, no. 2, pp. 2348-2362, 2013.

[17] V. Prabhavathi, J. S. Yadav, P. A. Kumar, and M. V. Rajam, "Abiotic stress tolerance in transgenic eggplant (Solanum melongena L.) by introduction of bacterial mannitol phosphodehydrogenase gene," Molecular Breeding, vol. 9, no. 2, pp. 137-147, 2002.

[18] M. Maheswari, Y. Varalaxmi, A. Vijayalakshmi et al., "Metabolic engineering using $m t l D$ gene enhances tolerance to water deficit and salinity in sorghum," Biologia Plantarum, vol. 54, no. 4, pp. 647-652, 2010.

[19] T. X. Nguyen, T. Nguyen, H. Alameldin, B. Goheen, W. Loescher, and M. Sticklen, "Transgene pyramiding of the HVA1 and $m t l D$ in T3 maize (Zea mays L.) plants confers drought and salt tolerance, along with an increase in crop biomass," International Journal of Agronomy, vol. 2013, Article ID 598163, 10 pages, 2013.

[20] B. Karakas, P. Ozias-Akins, C. Stushnoff, M. Suefferheld, and M. Rieger, "Salinity and drought tolerance of mannitolaccumulating transgenic tobacco," Plant, Cell \& Environment, vol. 20, no. 5, pp. 609-616, 1997.

[21] H. Rahnama, H. Vakilian, H. Fahimi, and B. Ghareyazie, "Enhanced salt stress tolerance in transgenic potato plants (Solanum tuberosum L.) expressing a bacterial mtlD gene," Acta Physiologiae Plantarum, vol. 33, no. 4, pp. 1521-1532, 2011.

[22] C. M. Sickler, G. E. Edwards, O. Kiirats, Z. Gao, and W. Loescher, "Response of mannitol-producing Arabidopsis thaliana to abiotic stress," Functional Plant Biology, vol. 34, no. 4, pp. 382-391, 2007.

[23] M. M. Chaves and M. M. Oliveira, "Mechanisms underlying plant resilience to water deficits: Prospects for water-saving agriculture," Journal of Experimental Botany, vol. 55, no. 407, pp. 2365-2384, 2004.

[24] P. Bhatnagar-Mathur, V. Vadez, and K. K. Sharma, “Transgenic approaches for abiotic stress tolerance in plants: retrospect and prospects," Plant Cell Reports, vol. 27, no. 3, pp. 411-424, 2008.

[25] T. Radhakrishnan, P. A. Kumar, N. R. Ghetia, J. R. Dobaria, and D. L. Parmar, "Genetic transformation of peanut using crylAc by Agrobacterium co-culture," in Proceedings of the International Symposium on Molecular Approaches for Improved Crop Productivity and Quality, p. 53, Tamil Nadu Agricultural University, Coimbatore, India, May 2002.

[26] R. Mehta, T. Radhakrishnan, A. Kumar et al., "Coat proteinmediated transgenic resistance of peanut (Arachis hypogaea L.) to peanut stem necrosis disease through Agrobacteriummediated genetic transformation," Indian Journal of Virology, vol. 24, no. 2, pp. 205-213, 2013.

[27] M. Pierce and K. Raschke, "Correlation between loss of turgor and accumulation of abscisic acid in detached leaves," Planta, vol. 148, no. 2, pp. 174-182, 1980.

[28] H. D. Barrs and P. E. Weatherley, "A re-examination of the relative turgidity technique for estimating water deficits in leaves," Australian Journal of Biological Sciences, vol. 24, pp. 519$570,1962$.

[29] M. Kumar, V. P. Chimote, R. Singh et al., "Development of Bt transgenic potatoes for effective control of potato tuber 
moth by using crylAb gene regulated by GBSS promoter," Crop Protection, vol. 29, no. 2, pp. 121-127, 2010.

[30] S. Tiwari, D. K. Mishra, A. Singh, P. K. Singh, and R. Tuli, "Expression of a synthetic crylEC gene for resistance against Spodoptera litura in transgenic peanut (Arachis hypogaea L.)," Plant Cell Reports, vol. 27, no. 6, pp. 1017-1025, 2008.

[31] M. Cheng, R. L. Jarret, Z. Li, and J. W. Demski, "Expression and inheritance of foreign genes in transgenic peanut plants generated by Agrobacterium-mediated transformation," Plant Cell Reports, vol. 16, no. 8, pp. 541-544, 1997.

[32] V. Prabhavathi and M. V. Rajam, "Mannitol-accumulating transgenic eggplants exhibit enhanced resistance to fungal wilts," Plant Science, vol. 173, no. 1, pp. 50-54, 2007.

[33] D. Pujni, A. Chaudhary, and M. V. Rajam, "Increased tolerance to salinity and drought in transgenic indica rice by mannitol accumulation," Journal of Plant Biochemistry and Biotechnology, vol. 16, no. 1, pp. 1-7, 2007.

[34] P. Nagabhyru, R. D. Dinkins, C. L. Wood, C. W. Bacon, and C. L. Schardl, "Tall fescue endophyte effects on tolerance to waterdeficit stress," BMC Plant Biology, vol. 13, no. 1, article 127, 2013.

[35] R. Hema, R. S. Vemanna, S. Sreeramulu, C. P. Reddy, M. SenthilKumar, and M. Udayakumar, "Stable expression of mtlD gene imparts multiple stress tolerance in finger millet," PLoS ONE, vol. 9, no. 6, Article ID e99110, 2014.

[36] S.-Y. Zhu, X.-C. Yu, X.-J. Wang et al., "Two calcium-dependent protein kinases, CPK4 and CPK11, regulate abscisic acid signal transduction in Arabidopsis," Plant Cell, vol. 19, no. 10, pp. 30193036, 2007.

[37] X. Zhang, L. Wang, H. Meng, H. Wen, Y. Fan, and J. Zhao, "Maize ABP9 enhances tolerance to multiple stresses in transgenic Arabidopsis by modulating ABA signaling and cellular levels of reactive oxygen species," Plant Molecular Biology, vol. 75, no. 4-5, pp. 365-378, 2011.

[38] A. C. Rai, M. Singh, and K. Shah, "Engineering drought tolerant tomato plants over-expressing BcZAT12 gene encoding a $\mathrm{C}_{2} \mathrm{H}_{2}$ zinc finger transcription factor," Phytochemistry, vol. 85, pp. 4450, 2013.

[39] X. Duan, Y. Song, A. Yang, and J. Zhang, "The transgene pyramiding tobacco with betaine synthesis and heterologous expression of AtNHX1 is more tolerant to salt stress than either of the tobacco lines with betaine synthesis or AtNHX1," Physiologia Plantarum, vol. 135, no. 3, pp. 281-295, 2009.

[40] C. X. Hou and Z. C. Tang, "Function and mechanism of compatible solutes," Plant Physiology Communications, vol. 35, p. 1, 1999.

[41] E. Keunen, D. Peshev, J. Vangronsveld, W. van den Ende, and A. Cuypers, "Plant sugars are crucial players in the oxidative challenge during abiotic stress: extending the traditional concept," Plant, Cell \& Environment, vol. 36, no. 7, pp. 1242-1255, 2013.

[42] T. Sarkar, T. Radhakrishnan, A. Kumar, G. P. Mishra, and J. R. Dobaria, "Heterologous expression of the AtDREB1A gene in transgenic peanut-conferred tolerance to drought and salinity stresses," PLoS ONE. In press.

[43] C. C. Holbrook, P. Ozias-Akins, Y. Chu, and B. Guo, "Impact of molecular genetic research on peanut cultivar development," Agronomy, vol. 1, no. 1, pp. 3-17, 2011. 